\title{
An autosomal dominant syndrome of uveal colobomata, cleft lip and palate, and mental retardation
}

\author{
H M KINGSTON, P S HARPER, AND P W JONES \\ From the Section of Medical Genetics, Department of Medicine, Welsh National School of Medicine, \\ Heath Park, Cardiff CF4 $4 X W$.
}

SUMMARY This report details a family in whom there is autosomal dominantly inherited uveal colobomata, associated eye defects, and cleft lip and palate occurring in twelve subjects over three generations. Considerable variability in expression of the gene is apparent, uveal colobomata being the most constant feature, and the full syndrome probably includes mental retardation of varying degree. The possibility of association with neural tube defect is discussed.

Uveal colobomata are well known to follow autosomal dominant inheritance, although sporadic and $\mathrm{X}$ linked types have been described..$^{1-3}$ There is also an association between colobomata and cleft lip and palate, usually occurring in sporadic cases. ${ }^{3}$ This family appears unique in demonstrating autosomal dominant inheritance of uveal colobomata with cleft lip and palate. The eye defects in this family have previously been published by Collum. ${ }^{4}$ This further report includes cleft lip and palate as a manifestation of the single gene defect, together with mental retardation of a variable degree, and suggests a possible association with neural tube defect.

\section{Case reports}

The family was ascertained through the proband (III.12) and the pedigree obtained (fig 1).

Patient I.1, a 54-year-old woman, had bilateral typical iris colobomata involving the choroid on both sides (fig 2). The right lens showed cortical opacities in the quadrant beneath the coloboma. On the left there was a complete cataract and ultrasonic scan demonstrated a detached retina.

Patient II.1, a 36-year-old woman, had a microophthalmic left eye with typical iris coloboma extending to the disc and macula, with no useful vision. The right eye was normal.

Received for publication 5 March 1982.
Patient II.2, a 33-year-old woman, had bilateral colobomata involving the iris and choroid plus the

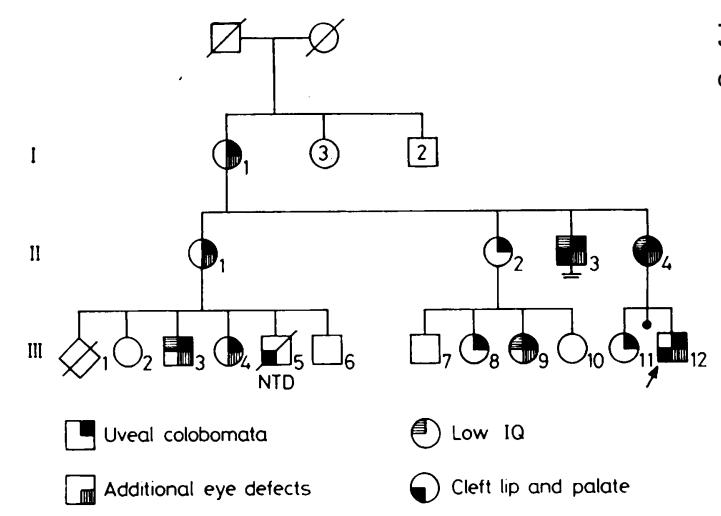

FIG 1 Pedigree of family.

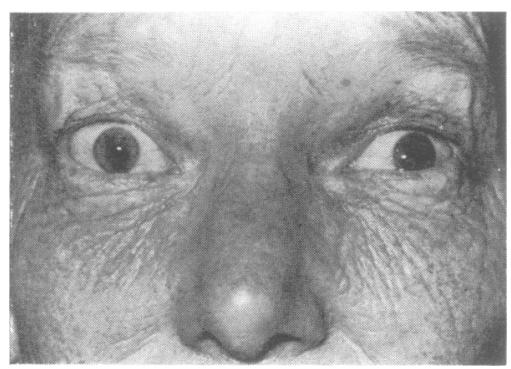

FIG 2 Typical iris colobomata with unilateral cataract. 
right optic disc, with visual acuity restricted to hand movements on that side.

Patient II.3, a 34-year-old man, was resident in an institution for the mentally handicapped in South Africa. He is stated to have had bilateral microphthalmos with iris colobomata and poor sight, unilateral cleft lip and palate, and severe mental retardation.

Patient II.4, a 31-year-old woman with a low IQ, had a repaired unilateral cleft lip and palate, with right microphthalmos, aniridia, and ptosis. A cosmetic lens had been worn in the right socket from the age of 10 years. Chromosome analysis was normal.

Patient III.3, a 15-year-old boy, had minimal left choroidal coloboma and right ptosis. He had poor school progress, attending a special school, followed by remedial teaching in a normal school.

Patient III.4, a 13-year-old girl, had bilateral microphthalmos with colobomata extending to the choroid on both sides. The pupils were ectopic, she had posterior embryotoxon, and bilateral glaucoma.

Patient III.5, a stillborn anencephalic baby, had a cleft lip and palate, but no record of ocular state was made in the hospital notes.

Patient III.8, a 12-year-old girl, had bilateral typical colobomata involving the iris and choroid.

Patient III.9, an 11-year-old girl, had a right coloboma affecting the iris and choroid with hypermetropia and a convergent squint, a left choroidal coloboma, and bilateral posterior embryotoxon. She was making poor progress at school and required remedial teaching.

Patient III.11, a 6-year-old girl, had bilateral colobomata affecting the iris and choroid.

Patient III.12, the proband, had a unilateral cleft lip and palate, right microphthalmos, and coloboma affecting the iris and choroid. Developmental progress was slow at one year of age. Chromosome analysis was normal.

\section{Discussion}

As reported by Collum, ${ }^{4}$ the eye defects in this family are very variable, the uveal colobomata being associated with microphthalmos, lens opacities and cataract, retinal detachment, posterior embryotoxon, glaucoma, and ptosis.

Four members of this family had cleft lip and palate and association with uveal colobomata is most probably attributable to the same single gene defect. These two defects occur together in other circumstances, notably in autosomal trisomies. James et $a l^{3}$ described colobomatous syndromes in 20 of 25 patients with uveal colobomata seen at the Hospital for Sick Children, Great Ormond Street, London, over a 10-year period. In five cases uveal colobomata were associated with cleft lip and palate or isolated cleft palate. No chromosomal abnormalities were identified and all cases were apparently sporadic. Ocular colobomata and cleft lip and palate also occur together in naso-ocular clefts ${ }^{5}$ and in association with congenital heart disease. ${ }^{6}$ Zuppinger et $a l^{7}$ reported a case with cleft lip, choroidal coloboma, and multiple hypothalamopituitary dysfunction, and recommended exclusion of hypopituitarism in such patients. Other syndromes have been described in which these two abnormalities are associated. Phillips and Lloyd Griffiths ${ }^{8}$ reported macular colobomata, cleft palate, and skeletal abnormalities inherited as an autosomal recessive trait, and Abruzzo and Erickson ${ }^{9}$ suggested $X$ linked or autosomal dominant inheritance with limited expression in females, for a syndrome including cleft palate, colobomata, hypospadias, deafness, short stature, and radial synostosis.

One member of this family (II.3) had severe mental retardation and was in an institution. Three others had mild mental retardation with schooling problems requiring remedial teaching and the proband was showing delayed developmental progress at one year. It seems likely that mental retardation is a further variable feature of the syndrome in this family.

The anencephalic baby born to patient II.1 had cleft lip and palate, but without observation on the ocular state it is not possible to say whether this baby also had the colobomatous syndrome; however, the possibility of neural tube defect associated with the other abnormalities manifest in this family nevertheless arises.

The association of cleft lip and palate with anencephaly is higher than would be expected by chance. ${ }^{10}$ An explanation for this lies in the fact that during embryonal development neural crest cells migrate into the facial region to form components of the craniofacial complex. Experimental irradiation in developing mice reduces the number of migrating neural crest cells, resulting in facial clefts and other nasofrontal deficiencies. The mass of neural plate remaining is concomitantly reduced resulting in brain and eye defects. ${ }^{11}$ If neural tube defect is 
associated with the syndrome in this family, the single gene must be exerting its effect at a critical time, or on a process involved in embryonic fusion. Although a critical stage in craniofacial embryogenesis occurs just before $\mathbf{3 0}$ days when the neural tube is nearly closed, it is difficult to postulate a critical timing for the effect of the aberrant gene to explain all the abnormalities of this syndrome, since the iris normally develops in the later part of the third month.

However, genetic factors may operate through intracellular regulatory mechanisms which influence cell differentiation and fusion processes. The mode of genetic influence remains unclear, but it is likely that RNA transcription and translation plays a part.

Whether or not neural tube defect is an integral part of the disorder in this family will not be clarified until information is available from future generations or from other case reports.

We wish to thank Dr B M Ansari of East Glamorgan Hospital for referral of the proband.

\section{References}

1 McKusick VA. Mendelian inheritance in man. Baltimore' London: Johns Hopkins University Press, 1978:74.

2 Goldberg MF, McKusick VA. X-linked colobomatous microphthalmos and other congenital anomalies. $\mathrm{Am} \mathrm{J}$ Ophthalmol $1971 ; 71: 1129-33$.

3 James PLM, Karseras AG, Wybar KC. Systemic associations of uveal colobomata. Br J Ophthalmol 1974;58: 917-21.

4 Collum LMT. Uveal colobomata and other anomalies in three generations of one family. Br J Ophthalmol 1971; $55: 458-61$.
5 Bartels RJ, O'Malley JE, Baker JL, Douglas WM. Naso-ocular clefts. Plast Reconstr Surg 1971;47:351-3.

6 Ho CK, Kaufman RL, Podos SM. Ocular colobomata, cardiac defect, and other anomalies. A study of seven cases including two sibs. J Med Genet 1975;12:289-92.

7 Zuppinger KA, Sutter M, Zurbrügg RP, Joss EE, Oetliker O. Cleft lip and choroidal coloboma associated with multiple hypothalamo-pituitary dysfunctions. J Clin Endocrinol 1971;33:934-9.

8 Phillips CI, Lloyd Griffiths D. Macular coloboma and skeletal abnormality. Br J Ophthalmol 1969;53:346-9.

9 Abruzzo MA, Erickson RP. A new syndrome of cleft palate associated with coloboma, hypospadias, deafness, short stature and radial synostosis. J Med Genet 1977; 14:76-80.

10 Gorlin RJ, Červenka J, Pruzansky S. Facial clefting and its syndromes. In: Bergsma D, ed. Birth defects: original article series. Vol VII, No 7. Baltimore: Williams and Wilkins, 1971:3-49.

11 Stewart RE. Genetic factors in craniofacial morphogenesis. In: Stewart RE, Prescott GH, eds. Oro facial genetics. St Louis: Mosby, 1976:46-66.

Requests for reprints to Dr H M Kingston, Section of Medical Genetics, Department of Medicine, Welsh National School of Medicine, Heath Park, Cardiff CF4 4XW.

\section{Addendum}

Since the initial report of this family was submitted for publication, a further female infant has been born to subject II.4. This baby has bilateral cleft lip and palate and bilateral severe microphthalmos/ anophthalmos with short palpebral fissures, entropian, and no cornea or eye ball visible during examination under anaesthesia. 